\title{
Comparing the Effect of Septoplasty with and without Nasal Packing on Outcomes and Complications of Surgery
}

\author{
Elnaz Shariatpanahi 1(D), Sahar Yousefnejad *1 (D), Abbas Moradi 2 (D)
}

1. Hearing Disorders Research Center, Besat Hospital, Hamadan University of Medical Sciences, Hamadan, Iran.

2. Dept. of Community and Family Medicine, School of Medicine, Hamadan University of Medical Sciences, Hamadan, Iran.

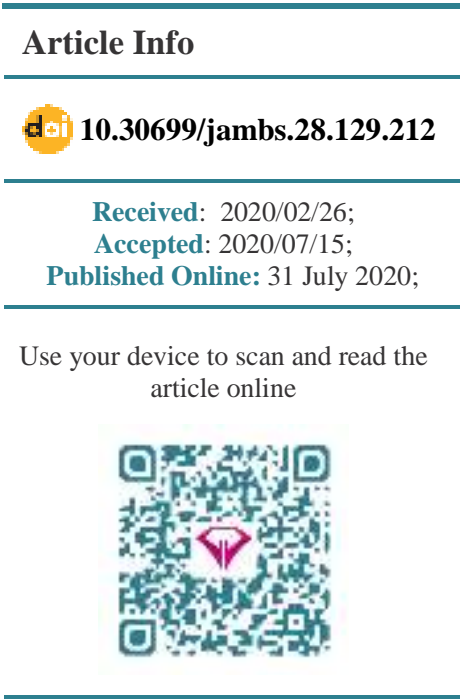

Corresponding Information: SaharYousefnejad, Hearing Disorders Research Center, Besat Hospital, Hamadan University of Medical Sciences,Hamadan, Iran E-Mail: m.namadian@zums.ac.ir

\begin{abstract}
Background \& Objective: Septoplasty is one of the most common nasal surgeries. After septoplasty, the nasal pack is routinely used to control bleeding, which can lead to complications such as pain and anxiety. This study aims to compare the effect of septoplasty with and without nasal packing on outcomes and complications of the surgery.
\end{abstract}

Materials \& Methods: In this randomized clinical trial, 50 patients undergoing septoplasty surgery at Besat Hospital, Hamadan, Iran, (during 2018 and 2019) were selected among the patients and randomly allocated in two groups of septoplasty with nasal pack (group A, 25 patients) and septoplasty without nasal pack (group B, 25). Anxiety score, pain score, bleeding rate, hematoma, respiratory status and local infection were compared in both groups. Data were analyzed by SPSS 16.

Results: The incidence of complications of throat irritation, tearing and headache and facial pain during the first 24 hours after septoplasty in group A was $48 \%, 76 \%$ and $64 \%$, respectively, and in group B, it was $12 \%, 0 \%$ and $0 \%$, respectively $(P<0.05)$. Mean score of anxiety and pain in the patients during 24 hours and first week after septoplasty and mean score of nasal obstruction during 24 hours, first week and three months after septoplasty in group A were significantly higher than those in group B $(P<0.05)$.

Conclusion: The use of nasal packs following septoplasty can cause throat irritation, tearing, increased pain, anxiety and respiratory problems in patients and it seems to have no effects on the duration of bleeding during 24 hours after the surgery.

Keywords: Septoplasty, Nasal Packing, Facial Pain, Anxiety

\section{Introduction}

Multiple functions can be mentioned for nasal septum such as dividing nasal air channels into two separated nostrils in order to increase contact surface of inhaled air with nasal mucus, support dursum and keep the shape of columella and tip of the nose (1).

Septal deviation is a common cause of the unilateral nasal airway obstruction. The prevalence of nasal deviation has been reported at approximately $40 \%$ in some studies, using CT scan as diagnostic method (1). Nasal deviation can occur because of trauma to the nose or the middle face. When the complaint of patients from nasal deviation accords with the clinical findings, they often end with septoplasty (2), which is one of the current surgeries at ear, nose and throat clinics (3).

Nasal packing or tampon is widely used postoperatively for the purpose of nasal septum stabilization and control of bleeding (4). Although these two reasons are the most important justifications of using nasal packing, the supporting evidence for this claim is inconsistent (5).

Removing nasal packing would be painful and patients might worry about this pain, which will increase their anxiety (6).

Furthermore, numerous side effects of using nasal packing after septoplasty, such as reducing sleep quality, respiratory problems, decreasing density of saturated oxygen, ear complications and toxic shock syndrome, have been reported in various studies $(7,8)$.

Lower level of anxiety has been observed among the patients who have used stitches, instead of nasal packing, after septoplasty (9).

Considering technological developments, facilitation of surgery with minimum suffering and application of 
endoscope for septoplasty, using nasal tampon after the surgery not only seems unnecessary, but also causes discomfort and side effects in the patients (10).

This study aims to compare complications such as pain, bleeding, septal hematoma, synechia, anxiety and ear complications in the patients and also to compare the consequences of improving airway stenosis by septoplasty, with and without nasal packing.

\section{Materials and Methods}

This randomized clinical trial was carried out on septoplasty candidates during 2018 and 2020 at Besat Hospital, Hamadan, Iran. Samples were collected by convenience and consecutive sampling methods. They were divided into two groups: intervention group (septoplasty without tampon) and control group (septoplasty with tampon). Patients in the control group were stitched and packed as usual and samples of the second group were stitched without packing.

Our inclusive criteria were patients above 18 years old and candidate for septoplasty. Previous medical history of granulomatous disease, postoperative trauma, absence of patient to follow up the results for any reason and need for other operations such as FESS or turbinate surgery were considered as the exclusion criteria.

\section{Surgical Technique}

A Killian incision was made approximately 1 to $2 \mathrm{~cm}$ posterior to the caudal septal margin; submucoperichondrial and sub-mucoperiosteal flaps were elevated to reform the deviated septum in the cartilage and bone. At the end of septoplasty, all the elevated septal flaps would be sutured entirely with continuous mattresses.

\section{Data Collection Tools}

In this study, data collection tools included a questionnaire for demographic characteristics of the patients (age and gender); a checklist for data about bleeding, hematoma and localized infection; Beck anxiety inventory (BAI) containing 21 questions; the visual analogue scale for pain (VAS) and nasal obstruction and septoplasty effectiveness (NOSE) questionnaire. BAI scale is a self-report measure of anxiety, in which the total score is calculated by finding the sum of the 21 items. Score of 0-21 means low anxiety, score of 22-35 means moderate anxiety and score of 36 and above means potentially concerning levels of anxiety (11). NOSE includes 5 questions that assess the patients' respiratory status and scores range from 0 (no problem) to 4 (severe problem). The minimum score of each patient will be zero and maximum is twenty (12). Visual analog scale (VAS) for pain is a validated, subjective measure used for acute and chronic pain, in which scores are recorded by making a handwritten mark on a $10-\mathrm{cm}$ line that represents a continuum between "no pain" and "worst pain" (13).
The incidence rate was investigated for pain complications, bleeding, infection, septal hematoma, throat irritation, tearing, headache, face pain, ear discomfort, level of anxiety, pain score and nasal obstruction during three periods, including 24 hours, one week and three months after the surgery. The results were recorded using the developed questionnaires and checklists.

\section{Data Analysis}

After being filled out, the questionnaires were analyzed using SPSS 16 (SPSS Inc., Chicago, IL., USA). Descriptive information of the qualitative data was represented by ratio and percentage in the format of Tables and Figures. Chi-squared test was run in order to compare the incidence rate of postoperative complications and bleeding during the first 24 hours in both groups (with and without nasal packing), Student's t-test for measuring the average of anxiety score and Mann-Whitney (nonparametric) U test for comparing pain score and nasal obstruction (due to the non-normal distribution of data according to ShapiroWilk normality test) were employed. The significance level of $<0.05$ was suggested for this research.

\section{Results}

In this study, 50 patients were selected, out of which 25 patients underwent septoplasty with packing and 25 patients underwent septoplasty without packing with quilting sutures taken on the septum. The packing group included 18 males (72\%) and 7 females (28\%), and the suturing group consisted of 16 males (64\%) and 9 females $(36 \%)$. Both groups were similar in terms of gender $(P=0.544)$.

No case of infection, septal hematoma and ear discomfort was found in the intervention and control groups. The frequency of throat irritation, tearing, headache and face pain in packing group was significantly higher than that in suturing group $(P<0.05)$ during the first 24 hours after septoplasty (Table 1$)$.

In comparison with suturing group, the average score for the level of anxiety was significantly higher in packing group during the first 24 hours $(P<0.001)$ and one week after septoplasty $(P=0.021)$ (Table 2).

Compared with suturing group, the postoperative average pain score was significantly higher in packing group during the first 24 hours $(P<0.001)$ and one week after septoplasty $(P=0.022)$ (Table 3$)$.

The average nasal obstruction score was significantly higher in packing group during the first 24 hours $(P<0.001)$, one week $(P<0.001)$ and three months after septoplasty $(P<0.001)$ compared with suturing group (Table 4). 
All the patients in packing group bled for less than 30 min during the first 24 hours; but, in suturing group, $92 \%$ of the patients bled less than $30 \mathrm{~min}$ and $8 \%$ of them bled more than $30 \mathrm{~min}$ (Table 5). In suturing group, two patients bled at recovery, to whom ribbon gauze (mesh) soaked in phenylephrine was applied. Bleeding was controlled in one of them; but, nasal tampon was required for the second patient.

Table 1. Distribution of post septoplasty complication in with and without nasal pack groups

\begin{tabular}{|c|c|c|c|}
\hline \multirow{2}{*}{ Complications } & \multicolumn{2}{|c|}{ Group } & \multirow{2}{*}{ P-value } \\
\hline & With nasal pack n(\%) & Without nasal pack n $(\%)$ & \\
\hline \multicolumn{4}{|c|}{ Within first $24 \mathrm{hr}$ after septoplasty } \\
\hline Throat irritation & $12(48 \%)$ & $3(12 \%)$ & 0.005 \\
\hline Tearing & $19(76 \%)$ & $2(8 \%)$ & $<0.001$ \\
\hline Headache and face pain & $16(64 \%)$ & $2(8 \%)$ & $<0.001$ \\
\hline \multicolumn{4}{|c|}{ After a week of septoplasty } \\
\hline Throat irritation & $4(16 \%)$ & $1(4 \%)$ & 0.349 \\
\hline Tearing & $0(0 \%)$ & $0(0 \%)$ & 0 \\
\hline Headache and face pain & $0(0 \%)$ & $0(0 \%)$ & 0 \\
\hline \multicolumn{4}{|c|}{ After 3months of septoplasty } \\
\hline Throat irritation & $0(0 \%)$ & $0(0 \%)$ & 0 \\
\hline Tearing & $0(0 \%)$ & $0(0 \%)$ & 0 \\
\hline Headache and face pain & $0(0 \%)$ & $0(0 \%)$ & 0 \\
\hline
\end{tabular}

Table 2. Distribution comparison of patients mean anxiety score undergoing septoplasty in with and without nasal pack groups

\begin{tabular}{|c|c|c|c|}
\hline \multirow{2}{*}{ Time of evaluation } & \multicolumn{2}{|c|}{ Group } & \multirow[t]{2}{*}{ P-value ${ }^{*}$} \\
\hline & With nasal pack mean \pm sd & Without nasal mean \pm sd & \\
\hline $24 \mathrm{hr}$ after septoplasty & $14.56 \pm 5.48$ & $6.56 \pm 2.18$ & $<0.001$ \\
\hline 1 week later & $3.25 \pm 2.36$ & $2.00 \pm 1.44$ & 0.021 \\
\hline 3 months later & $1.33 \pm 1.34$ & $0.76 \pm 0.92$ & 0.093 \\
\hline
\end{tabular}

* t student test

Table 3. Comparison of mean pain score of patients undergoing septoplasty in with and without nasal pack groups

\begin{tabular}{cccc} 
Time of evaluation & \multicolumn{3}{c}{ Group $^{\text {P-value }^{*}}$} \\
\hline 24 hr after septoplasty & With nasal pack mean \pm sd & Without nasal mean \pm sd & $<0.001$ \\
\hline 1 week later & $5.16 \pm 1.70$ & $2.96 \pm 2.18$ & 0.022 \\
\hline 3 months later & $2.04 \pm 1.88$ & $0.84 \pm 0.85$ & 0.077
\end{tabular}

* Mann-Whitney test

Table 4. comparison of mean score of nasal obstruction (NOSE) in patients septoplasty in with and without nasal pack groups

\begin{tabular}{|c|c|c|c|}
\hline \multirow{2}{*}{ Time of evaluation } & \multicolumn{2}{|c|}{ Group } & P-value* \\
\hline & With nasal pack mean \pm sd & Without nasal mean \pm sd & \\
\hline $24 \mathrm{hr}$ after septoplasty & $16.60 \pm 2.60$ & $4.60 \pm 12.26$ & $<0.001$ \\
\hline 1 week later & $4.96 \pm 2.19$ & $1.88 \pm 0.66$ & $<0.001$ \\
\hline 3 months later & $1.56 \pm 0.92$ & $0.44 \pm 0.51$ & $<0.001$ \\
\hline
\end{tabular}

* Mann-Whitney test 
Table 5. Comparison of the degree of bleeding within 24 hour after septoplasty in the groups with and without nasal pack

\begin{tabular}{|ccc}
\hline Bleeding time within $\mathbf{2 4}$ hour & Group & Without nasal pack $\mathrm{n}(\%)$ \\
\hline Total duration of bleeding periods less than $30 \mathrm{~min}$ & $25(100 \%)$ & $23(92 \%)$ \\
\hline Total duration of bleeding periods more than $30 \mathrm{~min}$ & $0(0 \%)$ & $2(8 \%)$ \\
\hline Need to transfusion & $0(0 \%)$ & $0(0 \%)$ \\
\hline
\end{tabular}

\section{Discussion}

The postoperative bleeding in the patients without nasal tampon was minor and few of them needed tampon application (14). According to some research, using nasal packing leads to increase in pain, headache and sleep disorders after the surgery (15).

Applying nasal packing is painful and the patients' experience of this pain will increase their level of anxiety during the tampon removal (16).

Some researchers believe that applying nasal packing is not necessary for every patient after septoplasty $(17,18)$ and depends on patients' characteristics. For example, applying nasal packing would be advantageous for the patients with postoperative bleeding; but, for the patients who suffer from obstructive apnea during sleep, septoplasty without nasal packing will be more appropriate (18).

In the current study, patients in both groups including packing group and suturing group were similar in terms of gender. Complications such as throat irritation, tearing, headache and face pain were significantly higher in packing group than suturing group during the first 24 hours after septoplasty.

Compared with suturing group, the average score for the level of anxiety and the average pain score were significantly higher in packing group during the first 24 hours and one week after septoplasty. The average nasal obstruction score was significantly higher in packing group during the first 24 hours, one week and three months after the surgery than suturing group. No statistically significant difference was found in the two groups in terms of septal hematoma, infection, ear discomfort and amount of postoperative bleeding.

According to Ivanova et al. (2019), no hematoma and no case of synechia were reported during a six-month follow-up period (14). In the current study, maximum period of follow-up was three months. Our findings were comparable with those of the study carried out by Ivanova et al. who reported no case of septal hematoma and synechia in both groups.
Ramalingam et al. (2019) reported that pain, headache and sleep disorders were significantly higher in packing group (15). Although the sample size of our study was smaller than that of Ramalington, the results were comparable. In the present work, one of the items in the nasal obstruction evaluation questionnaire was the criterion for measuring sleep disorders. The average nasal obstruction score was significantly higher in packing group than suturing group.

Shah et al. (2018) reported that using nasal packing after septoplasty would increase synechia (19). In our study, no case of synechia was found in groups during the 3-month follow-up period.

Hydri et al. (2018) studied 120 patients between 15 and 18 years of age. The results showed that removing tampon during general anesthesia would create less anxiety in the patients than local anesthesia (16). Sahin et al. (2016) used Hamilton anxiety rating scale to investigate the influence of removing nasal tampon after septoplasty on the level of anxiety among 50 patients. There was a statistically significant increase in the patient anxiety levels during 48 hours after the operation before nasal packing removal compared with the patients without packing (20). Considering the results of previous studies, the current work showed that the average score for the level of anxiety was significantly higher in the patients with nasal packing, compared with suturing group, during the first 24 hours and one week after septoplasty. The difference was that, in the present work, BAI was used and the sample size was smaller.

In the study undertaken by Koc et al. in 2016 (18), the problems such as pain, bleeding, nasal obstruction, mucosal synechia and anesthesia complications were examined in the patients with and without nasal packing during the first week after septoplasty. The results revealed less bleeding and nasal obstruction in the patients without nasal packing and more pain and discharge in packing group. But, the groups' difference was not statistically significant.

Also, Kayahan et al. studied two groups of patients, with and without nasal packing (with different materials), who had undergone septoplasty. The results 
indicated that the patients without packing experienced less nasal congestion, sneezing, tearing, edema and sleep disorders during the first 4 days after the surgery. However, no statistically significant difference was reported between the two groups one week after the surgery (17). In contrast with the results of their study, a statistically significant difference was found in tearing and nasal congestion between packing and suturing groups in the present research.

A clinical trial done by Yadav et al. verified the efficiency of packing nasal and transseptal suturing after septoplasty in 60 patients. The patients with nasal packing experienced more headache, sleep disorders, ear discomfort and throat irritating and more septal hematoma were detected among suturing group. No patients in the two groups experienced local infection. The pain score of all the patients in packing group was 9-10. The researchers suggested applying sutures after septoplasty in order to avoid the complications and consequences of nasal packing (21). No case of infection or septal hematoma was detected among both groups in the current study and the study results were comparable with Yadav's findings in terms of pain, throat irritation and headache.

Cukurova et al. (2012) studied complications including pain, bleeding, synechia, septal perforation and septal hematoma after septoplasty with nasal packing among 697 cases in order to compare the consequences of transseptal suture. Compared with the patients without nasal packing, the average pain score was significantly higher in packing group. No statistically significant difference was found between the two groups in terms of synechia, amount of bleeding and septal perforation. No case of hematoma was detected among both groups. In order to increase patient satisfaction, researchers prefer the transseptal suturing technique (22). Although our sample size was smaller than Cukurova's one, the results of both study were comparable.

Execution of clinical trial and random assignment of patients in two intervention and control groups were the strengths of this study.

One limitation of this study was its small sample size. Furthermore, due to short follow-up period for the patients (three months maximum), it was impossible to verify long-term complications.

\section{Conclusion}

Applying nasal packing following septoplasty will cause throat irritation and tearing, and increase pain, anxiety and respiratory problems in the patients.
Apparently, it would not influence bleeding and its duration during the first 24 hours after the surgery. Thus, quilting sutures without anterior nasal packing or using absorbable packing is recommended in order to decrease pain and anxiety in patients after the surgery.

\section{Acknowledgments}

This article was extracted from a $\mathrm{PhD}$ dissertation on ear, nose and throat, approved by Ethics Committee of Hamedan University of Medical Sciences, Research and Technology Vice-Chancellor, under number IR.UMSHA.REC.1397.091.

This article was approved in Iranian Registry of Clinical Trials with ID: IRCT20130215009014N243.

Our thanks shall extend to all those who cooperated with us in project implementation and data collection.

\section{Conflict of Interest}

Authors declared no conflict of interest.

\section{References}

1. Behnoud F, Nasab MS, Alizamir A. Comparison of the frequency of old septal deviation in patients with and without traumatic nasal bone fracture. ActaMedicaIranica. 2010:304-7.

2. Flint PW, Haughey BH, Robbins KT,et al. Cummings otolaryngology-head and neck surgery e-book. Elsevier Health Sciences; 2014 Nov 28.

3. Ketcham AS, Han JK. Complications and management of septoplasty. OtolaryngolClin North Am. 2010;43(4):897-904. [DOI:10.1016/j.otc.2010.04.013]

4. Acıoğlu E, Edizer DT, Yiğit Ö, Onur F, Alkan Z. Nasal septal packing: which one? Europ Arch Oto-Rhino-Laryngol. 2012;269(7):1777-81. [DOI:10.1007/s00405-011-1842-1]

5. Dubin MR, Pletcher SD. Postoperative packing after septoplasty: is it necessary? OtolaryngolClin North Am. 2009;42(2):279-85. [DOI:10.1016/j.otc.2009.01.015]

6. Gencer ZK, Özkiriş M, Gencer M, Saydam L. Comparison of ropivacaine, bupivacaine, prilocaine, and lidocaine in the management of pain and hemorrhage during nasal pack removal. Am J Rhinol Allergy. 2013;27(5):423-5. [DOI:10.2500/ajra.2013.27.3945]

7. Muhammad IA, Nabil-ur R. Complications of the surgery for deviated nasal septum. J College Physic Surg-Pakistan. JCPSP. 2003;13(10):5658. 
8. Sedwick JD, Lopez AB, Gajewski BJ, Simons RL. Caudal septoplasty for treatment of septal deviation: aesthetic and functional correction of the nasal base. Arch Facial Plastic Surg. 2005;7(3):158-62.

[DOI:10.1001/archfaci.7.3.158]

9. Sari K, Gul AI, Kantekin Y, Karaaslan O, Gencer ZK. Transseptal suturing reduce patient anxiety after septoplasty compared to nasal packing. Acta Med (Hradec Kralove). 2016;59:133-6. [DOI:10.14712/18059694.2017.40]

10. Awan MS, Iqbal M. Nasal packing after septoplasty: a randomized comparison of packing versus no packing in 88 patients. Ear, Nose Throat $\mathrm{J}$. 2008;87(11):624-7.

\section{[DOI:10.1177/014556130808701108]}

11. Beck AT, Epstein N, Brown G, Steer RA. An inventory for measuring clinical anxiety: psychometric properties. J Consult Clin Psychol. 1988;56(6):893.

[DOI:10.1037/0022 006X.56.6.893]

12. Stewart MG, Witsell DL, Smith TL, Weaver EM, Yueh B, Hannley MT. Development and validation of the nasal obstruction symptom evaluation (NOSE) scale. Otolaryngol Head Neck Surg. 2004;130(2):157-63. [DOI:10.1016/j.otohns.2003.09.016]

13. Hawker GA, Mian S, Kendzerska T, French M. Measures of adult pain: Visual analog scale for pain (vas pain), numeric rating scale for pain (nrs pain), mcgill pain questionnaire (mpq), shortform mcgill pain questionnaire (sf-mpq), chronic pain grade scale (cpgs), short form-36 bodily pain scale (sf-36 bps), and measure of intermittent and constant osteoarthritis pain (icoap). Arthritis Care Res. 2011;63(S11):S240-52. [DOI:10.1002/acr.20543]

14. Ivanova P, Iliev G, Kerimov K, Genova P, Spasova B, Sapundzhiev N. Septoplasty with or without post-operative nasal packing. LaryngoRhino-Otologie. 2019;98(S 02):11308. [DOI:10.1055/s-0039-1686728]

15. Ramalingam V, Venkatesan R, Somasundaram S, Kandasamy K, Rajeswari M. A comparative study between septal quilting sutures without nasal packing and only nasal packing post-septal correction. Indian J Otolaryngol Head Neck Surg. 2019:1-6. [DOI:10.1007/s12070-019-01730-x]

16. Hydri AS, Alam MJ, Udaipurwala IH, Mirza F. Evaluation of anxiety during nasal pack removal in patients operated under local versus general anesthesia. Group. 2018;10:5.

17. Kayahan B, Ozer S, Suslu A, Ogretmenoglu O, Onerci M. The comparison of the quality of life and intranasal edema between the patients with or without nasal packing after septoplasty. Europ Arch Oto-Rhino-Laryngol. 2017;274(3):1551-5. [DOI:10.1007/s00405-016-4403-9]

18. Koç AEÖ, Babakurban ST, Kibar SS, Büyüklü F. A comparative study on nasal packing after septoplasty: does it matter in terms of patient comfort, bleeding, and crust or synechia formation? Kulak BurunBogazIhtisDerg. 2016;26(3):152-8.

[DOI:10.5606/kbbihtisas.2016.62444]

19. Shah G. Comparison of Septoplasty with and without Nasal Packing: Its Association with PostOperative Nasal Adhesion Formation. J Islamabad Med Dent College. 2018;7(3):169-73.

20. Sahin C, Aras HI. The effect of nasal packing removal on patients anxiety. Med Arch. 2015;69(6):393.

[DOI:10.5455/medarh.2015.69.393-395]

21. Yadav K, Ojha T, Gakhar S, Sharma A, Singhal A, Kataria V. Effectiveness of Nasal Packing in Trans-septal Suturing Technique in Septoplasty: A Randomized Comparative Study. Indian Journal of Otolaryngology and Head \& Neck Surgery. 2019 Nov 1;71(3):1765-9. [DOI:10.1007/s12070-017-1111-8]

22. Cukurova I, Cetinkaya E, Mercan G, Demirhan E, Gumussoy M. Retrospective analysis of 697 septoplasty surgery cases: packing versus transseptal suturing method. Actaotorhinolaryngologicaitalica. 2012;32(2):111.

\section{How to Cite This Article:}

Shariatpanahi E, Yousefnejad S, Moradi A. Comparing the Effect of Septoplasty with and without Nasal Packing on Outcomes and Complications of Surgery. J Adv Med Biomed Res. 2020; 28 (129) :212-217

Download citation:

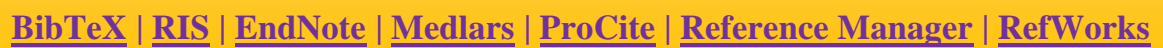

Send citation to:
Mendeley
Zotero
OHefworka RefWorks 